\title{
ITAIPU E PODER: POLÍTICOS E ATORES NA GESTÃO INSTITUCIONAL ${ }^{1}$
}

\author{
Marcelo Gonçalves Marcelino²
}

- Enviado em 04/02/2016

- Aprovado em 21/02/2016

A partir do controle burocrático-militar no contexto de ampliação das disputas da guerra fria o planejamento estratégico passou a tomar a direção de um discurso em favor da defesa, isto é, em nome da segurança nacional, onde os fatores geopolíticos estratégicos passariam a vigorar como sendo cruciais para o futuro da nação enquanto ator relevante no contexto geopolítico regional.

O continente sul-americano, em particular o chamado "cone sul”, onde Argentina, Uruguai, Paraguai e Brasil estão inseridos, já experimentava um período turbulento de ingerências externas; principalmente capitaneadas pelos Estados Unidos. A partir da tomada de poderes pelos militares no Brasil o projeto geopolítico abarcava diversos acordos bilaterais e multilaterais entre as nações vizinhas, no sentido de responder sinergicamente as insurgências "subversivas" patrocinadas pela ideologia vinculada ao socialismo real, e por outro, a uma demanda de interesse puramente nacional na direção do alargamento das suas bases de infraestrutura econômica, fundamental para $\mathrm{o}$ crescimento e desenvolvimento da nação brasileira aos moldes de como pensavam as elites cosmopolitas da época.

Desta forma, o setor energético surgia como uma necessidade urgente no sentido de viabilizar os projetos de expansão da infraestrutura produtiva brasileira. O governo militar entendia

\footnotetext{
${ }^{1}$ Pesquisa de doutorado em andamento sob a orientação da Professor Doutor Ricardo Costa de Oliveira no Programa de Pós-graduação em Sociologia da UFPR.

${ }^{2}$ Graduado em Ciências Econômicas, especialista em Sociologia Política, mestre e doutorando em Sociologia, todos pela UFPR. Endereço eletrônico: mgmarcelino10@yahoo.com.br
} 
que um projeto de grande monta poderia abrigar os interesses do Brasil e do Paraguai no sentido da viabilidade do fornecimento de energia elétrica para os dois países, e, ao mesmo tempo, serviria para demarcar fronteiras estratégicas e esvaziar as disputas fronteiriças na Bacia do Prata que se acirraram entre os dois países em 1966, e, ainda, impulsionar na prática a ideologia propagada da chamada "Doutrina de Segurança Nacional” que procurava justificar essa política através de obras públicas e projetos de desenvolvimento econômico, que nem sempre expressavam melhorias sociais que justificassem tal empreendimento.

Destas disputas e da própria conjuntura do período surge um entendimento para construir a hidrelétrica de Itaipu na Bacia do Prata, mais precisamente no rio Paraná, entre o Brasil e o Paraguai. Então, aos vinte e dois de junho de 1966, o Ministro de Estado das Relações Exteriores dos Estados Unidos do Brasil, Embaixador Juracy Magalhães e o Ministro das Relações Exteriores do Paraguai, Doutor Raúl Sapena Pastor assinaram uma Ata Final e trocaram Memorandos.

Apesar de um terceiro ator importante, no caso a Argentina ter inúmeras vezes tentado inviabilizar tal empreendimento desde o início das negociações, o acordo entre Brasil e Paraguai para a construção da Usina binacional foi sancionado. Esse desconforto ou desconfiança do lado argentino arrastou as discussões até o ano de 1979 onde um acordo tripartite entre os três países foi finalmente celebrado.

O Plano Nacional de Desenvolvimento (PND I) articulado e posto em prática na transição para o governo do presidente Médici contribuiu no processo de construção ou retomada das bases do desenvolvimentismo da década de 1950. Isso possibilitou o avanço das negociações em torno da construção da Usina Hidrelétrica de Itaipu que culminou na assinatura do Tratado de Itaipu em 26 de abril de 1973; instrumento legal que garantia o aproveitamento hidráulico do potencial do rio Paraná.

A necessidade de fôlego na direção da viabilização de projetos públicos como forma de continuar o crescimento econômico dos primeiros anos da década de 1970 (período do "milagre econômico") e também do desenvolvimento da infraestrutura necessária em um novo estágio de industrialização, além dos problemas causados pelo primeiro choque do petróleo mundial promovido pelo cartel da Organização dos Países Produtores e Exportadores de Petróleo (OPEP) impulsionaram a busca pelo aumento da intensidade dos investimentos públicos, em especial, 
projetos que envolveram a energia nuclear, hidrelétrica e também a matriz do combustível, como o caso da viabilização do Programa Pró-álcool a partir de 1973.

Essa fase desenvolvimentista burocrático-militar chega ao seu ápice no PND II do presidente Geisel onde os empréstimos internacionais aumentaram de forma avassaladora para dar conta de duas usinas atômicas (Angra I, II ), dos projetos de infraestrutura rodoviária como a ponte Rio-Niterói (RJ) e da obra faraônica da usina hidrelétrica de Itaipu. Obras inacabadas como a rodovia Transamazônica e a usina de Angra III, que ainda hoje está sendo construída, são também marcas desse período.

A Itaipu consagra a fase desenvolvimentista da ditadura, onde, na primeira fase é assinado o tratado de Itaipu em 1973 e outra no início do governo Geisel quando a Itaipu é criada em maio de 1974 como empresa binacional tanto para construir quanto gerenciar a usina.

A partir desse momento de transição combinados por períodos demarcados pela ideologia desenvolvimentista autoritária guiada pela cápsula do Estado indutor e seus respectivos instrumentos legais que começamos a investigar a empresa e seus atores principais no âmbito do domínio do processo decisório em nível político e econômico, sem esquecer das suas imbricações e conformações com a sociedade no plano estadual.

Diante do contexto atual, a empresa Itaipu Binacional surge como uma das principais instituições responsáveis pela infraestrutura nacional e o seu estudo a partir da perspectiva sociológica dos atores envolvidos são cruciais para entendermos as possíveis relações existentes entre a história de vida dos indivíduos que assumem postos chave na condução das políticas públicas das instituições e suas tomadas de decisões, assim como, propicia estabelecer conexões entre os grupos que detém o poder e os negócios privados via instituições públicas.

Trata-se de incorporar a análise das instituições e suas políticas públicas o instrumental sociológico, relacionando as biografias dos indivíduos e sua respectiva classe social, com seus comportamentos, ações e realizações no interior do aparelho de Estado, principalmente quando essa instituição tornou-se uma das mais relevantes no que diz respeito a construção de políticas estratégicas de desenvolvimento em tempos de disputas pelos espaços e fluxos de recursos naturais que percorrem geograficamente as entranhas das nações envolvidas pelos interesses em comum do Mercosul e das nações rivais. 
A Empresa Itaipu Binacional deve ser investigada e analisada a partir de um contexto amplo de inter-relações, onde cabem a abordagem histórica, econômica, política e sociológica, em que pesem a participação dos atores (gestores e políticos) no que tange a conquista e o domínio do aparelho estatal como célula de reprodução de mecanismos de controle e apropriação dos benefícios e privilégios que determinados agrupamentos sociais detém assim que são nomeados para assumirem cargos de envergadura na tecnocracia estatal e como condutores do processo político posicionados em altas hierarquias estratégicas.

A transição entre o regime militar e a democracia nas últimas décadas vem demonstrando que os atores envolvidos mudam, evidentemente, mas as suas ideias e realizações em torno da defesa dos seus interesses e de seus consortes permanece através de gerações de sucessores, independente dos partidos políticos a frente das mais diversas esferas de poder.

Políticos ou gestores considerados "outsiders" surgem e assumem postos nas instituições, mas certamente utilizam redes sociais interligadas, onde os mais variados interesses se colocam na busca e luta pelas suas demandas e espólios da sociedade civil (econômica e política) representada pelos privilégios e benefícios que as instituições provêm aqueles que as controlam. Quem assume esses cargos defendem interesses através de ações e realizações ao longo de seu itinerário a frente das instituições, e que, refletem as conformações de classe a que pertencem ou pretendem almejar através do domínio dessas megaestruturas, no caso da Itaipu Binacional, enquanto agentes políticos.

Desde a sua construção a Itaipu binacional passou por uma enorme transformação no que diz respeito as suas atribuições, dinamismo e importância como empresa estratégica que sempre foi desde o início. A Itaipu ainda se mantém como a maior hidrelétrica do mundo e sua principal função é gerar energia elétrica para Brasil e Paraguai. Ao mesmo tempo, nessas últimas, quatro décadas desde sua inauguração, a Itaipu tornou-se uma instituição ainda mais relevante ao investir e financiar projetos envolvendo os mais variados interesses e segmentos da economia e da sociedade civil.

As diversas conexões entre o campo político e econômico através dos atores políticos e agentes econômicos são representadas através de estruturas de poder amplas, onde cabem relações de parentesco, patronagem, relações ligadas a tecnoestrutura onde configuram-se algumas comunidades de técnicos e profissionais das diversas áreas em que permeiam os negócios e muitas 
tratativas com os empresariados e vários acertos e conciliações políticas ao longo da história como já mencionamos.

Para dar continuidade a esse processo as pessoas "corretas" devem assumir os cargos a elas designados como forma de assegurar o controle da administração pública nas mãos "hábeis" dos indivíduos "confiáveis" como forma de salvaguardar as conexões de interesse ao bom funcionamento das redes sociais coesas como forma de garantir os privilégios e as demandas que o poder político e econômico podem usufruir e proporcionar a classe dirigente e aos demais parceiros.

A partir dessa abordagem reforçamos a ideia de que para relacionar as tomadas de decisões de determinadas instituições e seus vínculos com as demais demandas complexas da sociedade caminharemos na direção de descobrir a história de vida (biografias) dos indivíduos que assumiram cargos relevantes a frente das instituições. Se executarmos essa tarefa com a devida apreciação podemos fazer uma incursão metodológica na direção de traçar uma pretensa biografia coletiva dos indivíduos que assumiram cargos importantes na direção da Itaipu binacional como ferramenta importante de análise sociológica. Desta forma, isso nos possibilitará compreender melhor as características comuns de um grupo de atores ao longo da história.

Esses atores e políticos são os indivíduos se apropriam dos mecanismos de controle, regulação e decisão sobre os assuntos que englobam as políticas de investimento, e, ainda, compartilham atribuições legais-institucionais nos aparelhos de Estado, procurando estabelecer a todo instante, vínculos com uma variedade de outros grupos de pressão e demais parceiros advindos de outras organizações locais, regionais, nacionais e até estrangeiras nos mais variados ramos de empreendimento. Esse processo passa a ser acompanhado antes mesmo da instauração dos pilares iniciais da construção da Itaipu Binacional e perpassa o âmbito histórico, político, social e econômico do período da ditadura civil-militar até chegar no presente, onde ocorrem as demais e diferentes lutas políticas em um ambiente democrático e de interesses geopolítico-estratégicos em nível sul-americano, e, ao mesmo tempo, diante de um contexto de disputas pelo poder e influência em tempos de globalização e busca por outras alternativas de capturar as fontes energéticas e de recursos naturais na região do cone sul. 